\title{
Anti-C1q autoantibodies deposit in glomeruli but are only pathogenic in combination with glomerular C1q-containing immune complexes
}

\author{
Leendert A. Trouw, ${ }^{1}$ Tom W.L. Groeneveld, ${ }^{1}$ Marc A. Seelen, ${ }^{1}$ Jacques M.G.J. Duijs, ${ }^{1}$ \\ Ingeborg M. Bajema, ${ }^{2}$ Frans A. Prins, ${ }^{2}$ Uday Kishore,, ${ }^{3}$ David J. Salant, ${ }^{4}$ J. Sjef Verbeek, ${ }^{5}$ \\ Cees van Kooten, ${ }^{1}$ and Mohamed R. Daha1 \\ 1Department of Nephrology and 2Department of Pathology, Leiden University Medical Center, Leiden, The Netherlands. \\ ${ }^{3}$ Weatherall Institute of Molecular Medicine, John Radcliffe Hospital, University of Oxford, Oxford, United Kingdom. ${ }^{4}$ Department of Medicine, \\ Evans Biomedical Research Center, Boston University Medical Center, Boston, USA. ${ }^{5}$ Department of Human Genetics, \\ Leiden University Medical Center, Leiden, The Netherlands.
}

\begin{abstract}
Anti-C1q autoantibodies are present in sera of patients with several autoimmune diseases, including systemic lupus erythematosus (SLE). Strikingly, in SLE the presence of anti-C1q is associated with the occurrence of nephritis. We have generated mouse anti-mouse $\mathrm{C} 1 \mathrm{q}$ mAb's and used murine models to investigate whether anti-C1q autoantibodies actually contribute to renal pathology in glomerular immune complex disease. Administration of anti-C1q $\mathrm{mAb} \mathrm{JL}-1$, which recognizes the collagen-like region of $\mathrm{C} 1 \mathrm{q}$, resulted in glomerular deposition of C1q and anti-C1q autoantibodies and mild granulocyte influx, but no overt renal damage. However, combination of JL-1 with a subnephritogenic dose of C1q-fixing anti-glomerular basement membrane (anti-GBM) antibodies enhanced renal damage characterized by persistently increased levels of infiltrating granulocytes, major histological changes, and increased albuminuria. This was not observed when a non-C1qfixing anti-GBM preparation was used. Experiments with different knockout mice showed that renal damage was dependent not only on glomerular $\mathrm{C} 1 \mathrm{q}$ and complement activation but also on Fc $\gamma$ receptors. In conclusion, anti-C1q autoantibodies deposit in glomeruli together with $\mathrm{C} 1 \mathrm{q}$ but induce overt renal disease only in the context of glomerular immune complex disease. This provides an explanation why anti-C1q antibodies are especially pathogenic in patients with SLE.
\end{abstract}

\section{Introduction}

Systemic lupus erythematosus (SLE) is a systemic autoimmune disease immunologically characterized by B cell hyperreactivity, production of a multitude of different autoantibodies, and immune complex formation $(1,2)$. It affects $0.04 \%$ of the general population of developed countries. Since nearly $80 \%$ of the cases occur in women in the childbearing years, it may affect as many as 1 in 1,000 young women (3). The etiology of SLE is largely unknown, but it involves genetic, hormonal, and environmental factors (4). The complement system plays an important role in the onset as well as the effector phase of $\operatorname{SLE}(5,6)$ and may also be the target of an autoantibody response (7). In SLE many organs may be affected, including serosa, joints, CNS, skin, and kidney.

Lupus nephritis (LN), the renal disease that accompanies SLE, is present in $25-50 \%$ of the cases (8) and is the major cause of morbidity and mortality (9). Understanding the sequence of events leading to full-blown LN in these patients is of major importance. Anti-C1q autoantibodies have been suggested to be closely associated with $\mathrm{LN}(10)$. This association is concluded from the correlation between

Nonstandard abbreviations used: CLR, collagen-like region; DIG, digoxigenin; Fc $\gamma$ R, Fc $\gamma$ receptor; GBM, glomerular basement membrane; gh, globular head; HUVS, hypocomplementemic urticarial vasculitis syndrome; LN, lupus nephritis; SLE, systemic lupus erythematosus

Conflict of interest: The authors have declared that no conflict of interest exists.

Citation for this article: J. Clin. Invest. 114:679-688 (2004)

doi:10.1172/JCI200421075.
anti-C1q autoantibody positivity and renal involvement $(11,12)$, the predictive value of anti-C1q autoantibody titers for flares of nephritis $(13,14)$, and the accumulation of anti-C1q autoantibodies in $\mathrm{LN}$ kidneys $(15,16)$. Conversely, in the absence of anti-C1q autoantibodies, no LN develops $(17,18)$. However, no causal relationship has been established until now. Anti-C1q autoantibodies may be associated with other immune complex renal diseases as well; however, the total number of patients studied limits firm conclusions (10). Interestingly, anti-C1q autoantibodies can be found in several other conditions as well, such as the hypocomplementemic urticarial vasculitis syndrome (HUVS), and even in some healthy individuals (10), but in these instances they are unrelated to renal pathology. Anti-C1q autoantibodies also occur in murine models of SLE $(19,20)$. In MRL-lpr mice, rising anti-C1q autoantibody titers parallel a rise in $\mathrm{LN}$, and anti-C1q autoantibodies also accumulate in glomeruli in murine SLE (21) as in human SLE.

In the present study we have investigated how anti-C1q autoantibodies contribute to the development of nephritis in mouse models. We show that administration of anti-C1q mAb's to naive mice results in glomerular deposition of $\mathrm{C} 1 \mathrm{q}$ and antiC1q autoantibodies but not in overt renal disease. However, administration of anti-C1q autoantibodies to mice pretreated with C1q-fixing anti-glomerular basement membrane (antiGBM) antibodies, as a model for glomerular immune complex disease, resulted in strong synergistic enhancement of renal disease. Therefore, anti-C1q autoantibodies can be pathogenic to 
the kidney but only in the context of C1q-containing glomerular immune complexes as found in SLE.

\section{Results}

Generation and characterization of anti-C1 $q m A b$ 's. Following immunization of $\mathrm{C} \mathrm{q}^{-/-}$mice with purified mouse $\mathrm{C} 1 \mathrm{q}$, we obtained several mouse anti-mouse C1q mAb's. The stable clones JL-1, JL-2, and JL-3 were of the IgG2b, IgG2a, and IgM isotypes, respectively. Purified Ig's reacted in a dose-dependent fashion with C1q in ELISA (Figure 1A). For all our experiments we used an IgG2b control mAb as negative control. All 3 anti-C1q $\mathrm{mAb}$ 's recognize different epitopes, since digoxigenin-conjugated (DIG-conjugated) mAb's were only competed by the respective unlabeled $\mathrm{mAb}$ but not by any of the other mAb's (Figure 1B). Anti-C1q mAb's were used to stain sections of spleens of WT mice and $\mathrm{C}_{1} \mathrm{q}^{-/-}$mice as an additional argument for specificity. Both mAb's JL-1 and JL-2 stain mouse C1q specifically on follicles of spleen of WT mice, as do polyclonal antibodies, but not on spleen of $\mathrm{C} \mathrm{q}^{-/-}$mice (Figure $1 \mathrm{C}$ ). Both mAb JL-3 (data not shown) and control mAb (Figure 1C) did not stain either the WT or the $\mathrm{C}_{1 \mathrm{q}^{-/}}$spleen. Western blot analysis showed that whereas the polyclonal antibody recognized all 3 chains of C1q, mAb JL-1 specifically recognized the $\mathrm{A} / \mathrm{B}$ chain and JL-2 recognized the $\mathrm{C}$ chain. Neither JL-3 nor IgG2b recognized C1q in Western blots (data not shown). In humans, anti-C1q autoantibodies react primarily with the collagen-like region (CLR), or "tail," of the C1q molecule $(10,21)$. Using recombinant heads or tails (CLRs), we found that JL-1, which was the only mAb showing cross-reactivity with human $\mathrm{C} 1 \mathrm{q}$ (data not shown), specifically recognized the CLR only (Figure 1D). Similarly, serum from autoimmune MRL-lpr mice, but not normal mouse serum, reacted dose-dependently with CLRs (Figure 1E). Based on these in vitro data we concluded that $\mathrm{mAb}$ JL-1 is the most appropriate anti-C1q $\mathrm{mAb}$ to test in vivo.

Anti-C1q mAb's deplete circulating C1q and deposit in glomeruli but do not induce overt renal damage. Administration of mAb JL-1 (1 mg intraperitoneally) resulted in complete depletion of circulating $\mathrm{C} 1 \mathrm{q}$ levels at 2 hours, which remained low at least up to 24 hours, whereas injection of IgG2b control $\mathrm{mAb}$ did not alter circulating C1q levels (Figure 2A). Administration of $\mathrm{mAb} J \mathrm{~L}-1$ resulted in an increased glomerular depo-

\section{Figure 1}

In vitro characterization of mouse anti-mouse $\mathrm{C} 1 \mathrm{q}$ mAb. (A) Anti-C1q detection ELISA for anti-C1q mAb's $\mathrm{JL}-1$, JL-2, and JL-3 and control mAb IgG2b under $0.5 \mathrm{M} \mathrm{NaCl}$ buffer conditions. OD415, OD at $415 \mathrm{~nm}$. (B) Epitope competition ELISA showing inhibition of binding of DIG-labeled anti-C1q mAb to mouse C1q by unlabeled anti-C1q mAb or control mAb IgG2b. (C) Immunohistochemistry of WT or $\mathrm{C}_{1 q^{-/}}$mouse spleen stained with anti-C1q mAb or controls. Original magnification, $\times 250$. Poly, polyclonal antibody. (D) C1q head domains of the human $A, B$, and $C$ chains or the control maltose-binding protein (MBP), CLRs, and intact human C1q were coated, and $\mathrm{mAb} \mathrm{JL}-1$ binding was analyzed. (E) Anti-C1q tail ELISA using human CLRs and serum of autoimmune MRL-Ipr mice (MRL-Ipr) or nonautoimmune normal mouse serum (NMS) for binding. sition of mouse IgG and especially mouse C1q, whereas injection of control $\mathrm{mAb}$ did not result in additional $\mathrm{IgG}$ or $\mathrm{C} 1 \mathrm{q}$ deposition (Figure 2, B and C). Administration of mAb JL-1 to $\mathrm{C}_{1} \mathrm{q}^{-/-}$mice did not result in enhanced glomerular IgG deposition, which excludes the possibility that $\mathrm{mAb} \mathrm{JL}-1$ is reacting with glomerular antigens other than C1q (Figure 2B). Administration of mAb JL-1 resulted in a mild but significant glomerular granulocyte influx (Figure 2D). However, none of the mice developed albuminuria (Figure 2E).

Anti-C1q mAb JL-1 deposits on to glomerular C1q in a planted antigenlike fashion. Previous studies (22) have demonstrated that Ig-deficient, Rag2-/- mice, when compared with WT mice, not only lack circulating IgG but also lack IgG in glomeruli. As a consequence these Rag $2^{-/-}$mice also lack glomerular $\mathrm{C} 1 \mathrm{q}$, since there is no glomerular IgG as a focus for glomerular C1q localization. Administration of JL-1 to Rag2-/- mice, which have comparable levels of circulating $\mathrm{C} 1 \mathrm{q}$, resulted in a similar depletion of circulating $\mathrm{C} 1 \mathrm{q}$ (Figure 3A). However, this did not lead to glomerular deposition of $\mathrm{C} 1 \mathrm{q}$ and anti-C1q autoantibodies as seen in WT mice (Figure $3, \mathrm{~B}$ and $\mathrm{C})$. Reconstitution of circulating IgG led to the presence of both IgG and C1q in glomeruli (Figure 3, B and C). Subsequent injection of these IgG-reconstituted mice with JL-1 induced glomerular deposition of $\mathrm{C} 1 \mathrm{q}$ and anti-C1q autoantibodies as seen in WT mice (Figure 3, B and C). These experiments show that JL-1
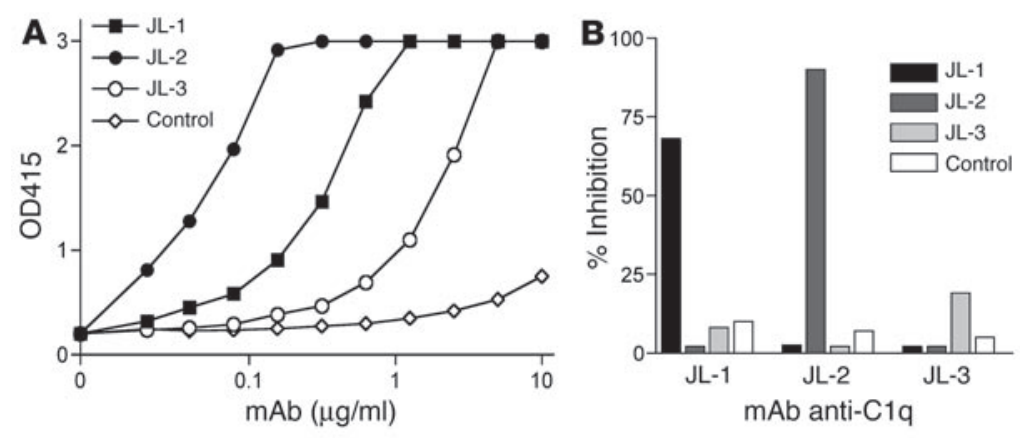

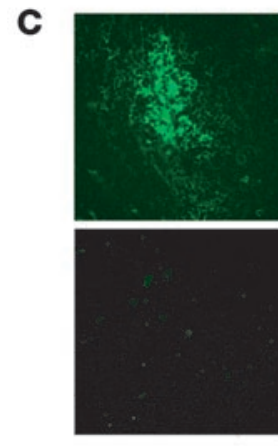

Poly
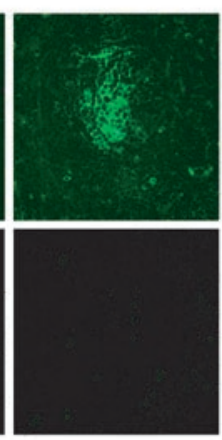

$\mathrm{JL}-1$
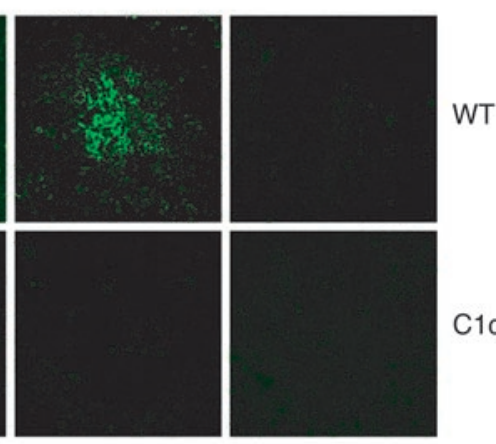

$\mathrm{JL}-2$

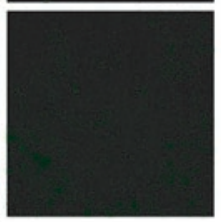

Control

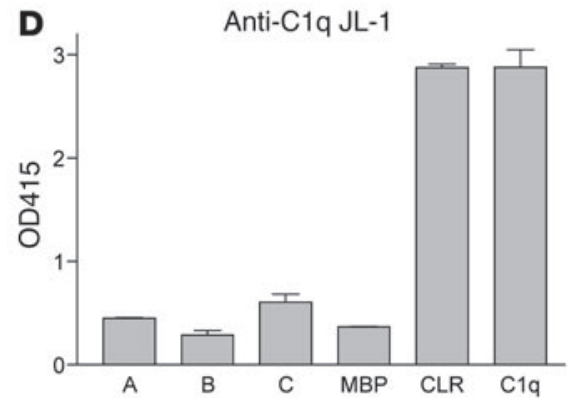

E

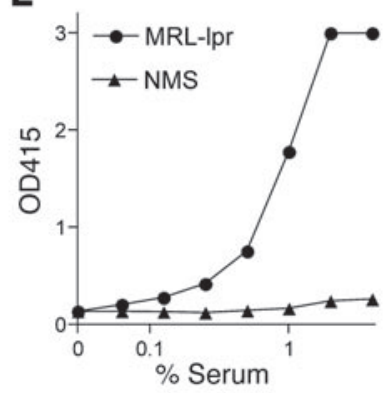


A
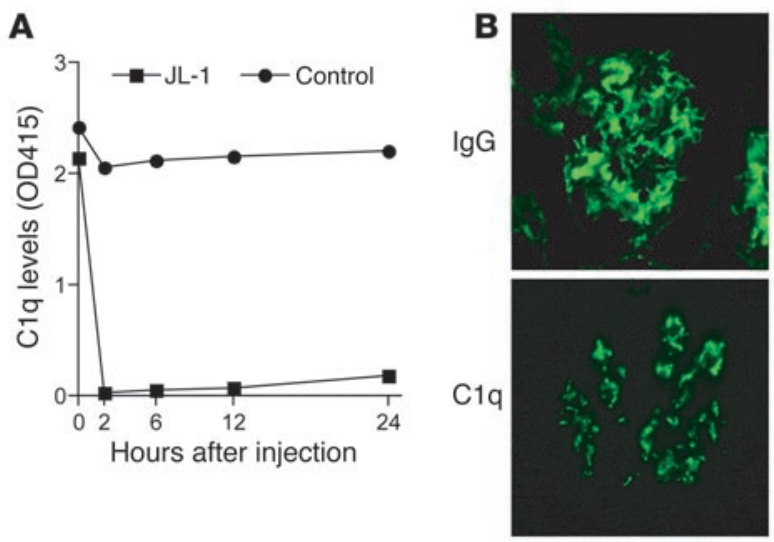

$\mathrm{WT}+\mathrm{JL}-1$
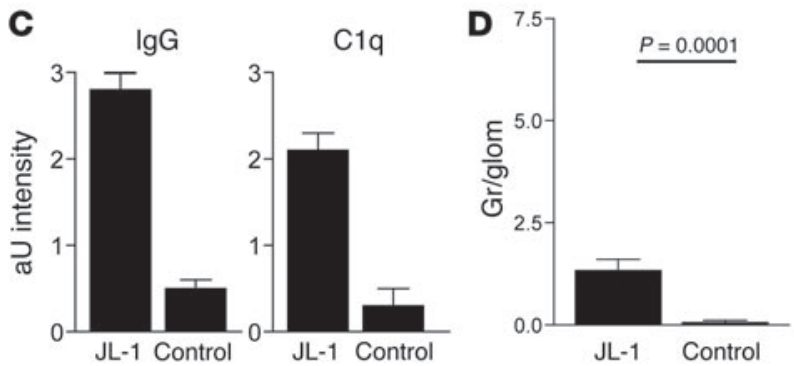

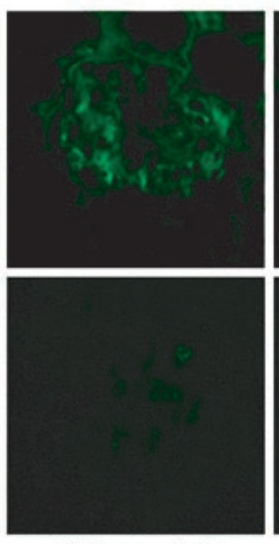

WT + control

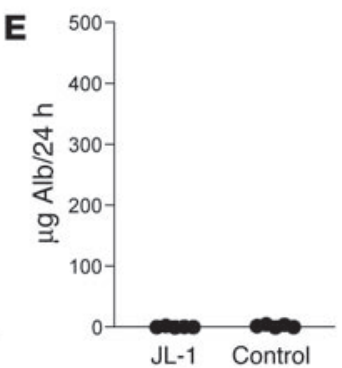

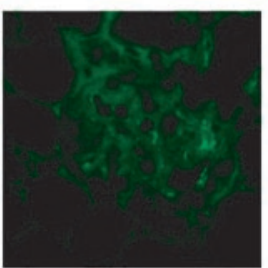

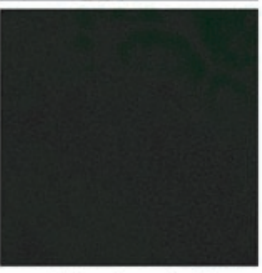

$\mathrm{C} 1 \mathrm{q}^{-1}+\mathrm{JL}-1$
Figure 2

Effects of administration of anti-C1q mAb to naive mice. (A) C1q sandwich ELISA for the detection of serum $\mathrm{C} 1 \mathrm{q}$ levels following administration of anti-C1q mAb and control mAb.(B) Immunofluorescence analysis of mouse kidneys stained for the presence of mouse $\mathrm{IgG}$ and mouse $\mathrm{C} 1 \mathrm{q}$ following administration of JL-1 or con-

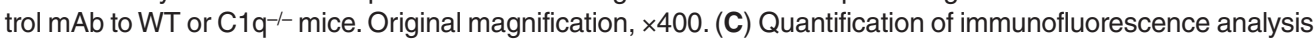
ods. (D) Quantification of glomerular granulocyte influx. Depicted on the $y$ axis are granulocytes per glomerular cross section (Gr/glom) at 24 hours after injection. (E) Assessment of albuminuria by ELISA. Alb, albumin. of the deposition of $\operatorname{IgG}$ and C1q in WT mice. Data are expressed as arbitrary units (aU), as described in Meth-

deposition of $\mathrm{mAb} J \mathrm{~L}-1$, in this model of immune complex glomerulonephritis, resulted in markedly increased albuminuria $(P=0.0026$ compared with IgG2b) (Figure 4D).

Mechanism of deposition of anti-C1q $m A b J L-1$ in combination with anti-GBM antibodies. We used $\mathrm{C}_{1} \mathrm{q}^{-/-}$mice to verify that the observed renal damage was dependent on $\mathrm{C} 1 \mathrm{q}$ and not caused by contaminating factors like endotoxin. Administration of the rabbit anti-GBM preparation to WT mice induced linear deposition of both rabbit IgG and mouse C1q in glomeruli. Administration of the same preparation to $\mathrm{C}_{1} \mathrm{q}^{-/-}$mice led to the linear deposition of only rabbit IgG, not mouse C1q (Figure 5A). In contrast to WT mice, $\mathrm{C}_{1 \mathrm{q}}{ }^{-/-}$mice did not display any enhancement of albuminuria upon coinjection of JL-1 (see Figure 8).

We next investigated the significance of serum $\mathrm{C} 1 \mathrm{q}$ versus glomerular $\mathrm{C} 1 \mathrm{q}$ in this model of glomerulonephritis. We compared a C1q-fixing rabbit anti-GBM preparation and a non-C1q-fixing sheep does not capture $\mathrm{C} 1 \mathrm{q}$ from the circulation and deposit in the glomerulus but that mAb JL-1 deposits on to $\mathrm{C} 1 \mathrm{q}$ already present in the glomerulus in a planted antigen-like fashion.

Administration of anti-C1q $m A b J L-1$ induces overt renal damage when combined with a subnephritogenic dose of anti-GBM antibodies. Since LN is characterized by the glomerular deposition of C1q-containing immune complexes, we tested the effect of JL- 1 in a murine model of C1q-containing solid-phase glomerular immune complexes. Administration of a subnephritogenic dose of C1q-fixing rabbit anti-mouse GBM antibodies was followed by administration of JL-1 or control mAb. Equal administration of anti-GBM antibodies was demonstrated by staining of renal sections for rabbit IgG (Figure 4, A and B). Administration of control mAb IgG2b directly following anti-GBM administration did not result in glomerular localization of additional mouse IgG or C1q and did not increase the mild albuminuria observed with this subnephritogenic dose of anti-GBM (Figure 4, A and D). In sharp contrast, mAb JL-1 gave a strong glomerular deposition of mouse IgG and also of additional C1q (Figure 4, A and B). This increase in IgG and C1q deposition involved all glomeruli (Figure 4A) and was highly consistent between individual mice (Figure 4, A and B). Confocal analysis following double staining for mouse IgG and mouse $\mathrm{C} 1 \mathrm{q}$ and for mouse IgG and rabbit IgG revealed that rabbit IgG was present on the GBM and that both mouse $\mathrm{C} 1 \mathrm{q}$ and mouse IgG (anti-C1q mAb) followed the same pattern (Figure 4C). Importantly, the glomerular
anti-GBM preparation. Administration of both antibody preparations induced linear deposition of anti-GBM antibodies, but linear deposition of mouse $\mathrm{C} 1 \mathrm{q}$ was only observed in the mice injected with C1q-fixing anti-GBM (Figure 5A). Administration of JL-1 to these mice enhanced renal damage only in the mice injected with C1q-fixing anti-GBM (Figure 5B). This points to a dependence on glomerular C1q.

Glomerular histological changes induced by anti-GBM and anti-C1q $m A b$ $J L-1$. In addition to causing albuminuria, administration of JL-1 in the model of C1q-containing glomerular immune complexes induced major histological changes in glomeruli analyzed 24 hours after injection, characterized by pronounced inflammatory cell influx, focal capillary tuft occlusion by microthrombi, necrotizing lesions, nuclear debris, and wireloop-like lesions (Figure 6A). We did not observe crescents, extracapillary proliferation, or mesangial proliferation. Glomeruli of mice coinjected with control mAb only displayed limited inflammatory cell influx. Quantification of histological changes was performed using the activity index as described by Austin et al. (23). The JL-1-coinjected mice consistently displayed a much higher activity index than the control-coinjected mice (Figure 6B). Electron microscopy revealed capillary tuft occlusion by either granulocytes or fibrinlike material in mice injected with antiGBM and JL-1, whereas in mice coinjected with control mAb IgG2b the capillaries showed normal contours, without alterations of the endothelium or GBM (Figure 6C). At higher magnifications, some 

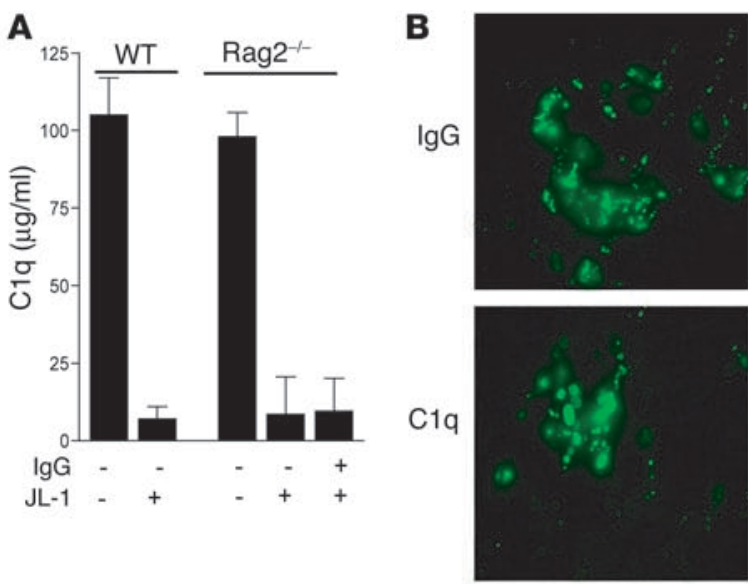

$\mathrm{PBS}+\mathrm{JL}-1$
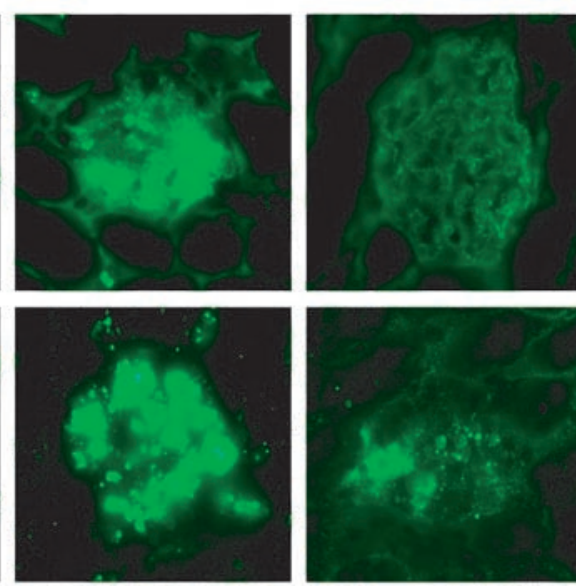

$\lg \mathrm{G}+\mathrm{JL}-1$

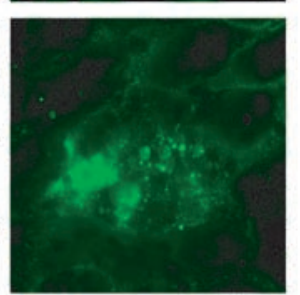

$\lg \mathrm{g}+\mathrm{PBS}$
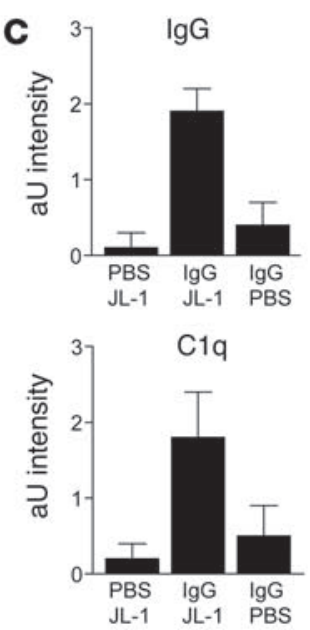

Figure 3

Anti-C1q autoantibodies react with $\mathrm{C} 1 \mathrm{q}$ in the glomerulus in a planted antigen-like fashion. (A) C1q sandwich ELISA for serum levels of C1q in

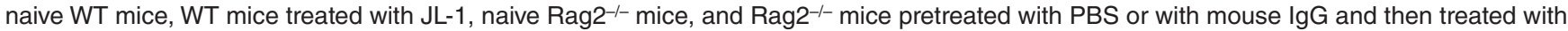
JL-1. (B) Immunofluorescence analysis of renal sections of Rag2 $2^{-1-}$ mice, either naive or reconstituted for mouse IgG followed by injection of either JL-1 or PBS. Images show the absence of IgG and C1q in naive Rag $2^{-/-}$mice and positivity for IgG and C1q, both mesangially and along the GBM, in IgG-reconstituted mice. The positivity for $\operatorname{lgG}$ and $\mathrm{C} 1 \mathrm{q}$ is highly increased following administration of $\mathrm{JL}-1$. Original magnification, $\times 400$. (C) Quantification of immunofluorescence analysis of the glomerular deposition of IgG and C1q.

subendothelial electron-dense deposits (wireloop-like lesions) were seen in mice injected with anti-GBM and JL-1 but not in mice coinjected with the control mAb IgG2b (Figure 6C).

Glomerular granulocyte influx is pronounced and extended in JL-1injected mice. Analysis of renal sections of mice injected with antiGBM in combination with either mAb JL-1 or IgG2b for granulocytes revealed significantly more infiltrating granulocytes at both 2 and 24 hours after injection in the JL-1-injected mice compared with the IgG2b-injected mice (Figure 7A). Granulocyte influx in this model of anti-GBM nephritis is known to peak at 2 hours after injection and then to diminish over time (24). Strikingly, the granulocyte influx at 24 hours was maintained in the JL-1-injected mice and was decreased, as expected, in the IgG2b-injected control mice (Figure 7A). Using confocal microscopy, we confirmed the increased number of infiltrating granulocytes (Figure 7B). Interestingly, the staining for granulocytes occasionally colocalized with the linear deposition of C1q (Figure 7B; colocalization in white; see arrow).

Requirements for JL-1 in combination with anti-GBM to enhance renal disease. To investigate the requirements for the enhanced renal injury and albuminuria, the combination of the C1q-fixing anti-GBM preparation and JL- 1 was administered to various mice genetically deficient for complement components or Fcy receptors. We found that the enhanced albuminuria was dependent on complement activation, based on the observations in $\mathrm{C}^{-/-}$mice. Potentially, complement may be activated via 3 pathways, the classical, alternative, and lectin pathways of complement activation. Since $\mathrm{C}^{-/-}$mice were also protected, either the classical or the lectin pathway was activated (Figure 8). In addition to complement activation albuminuria in this model is also dependent on $\mathrm{Fc} \gamma$ receptor $(\mathrm{Fc} \gamma \mathrm{R})$, since injection of anti-GBM in combination with $\mathrm{mAb} \mathrm{JL}-1$ did not result in any albuminuria in Fc $\gamma$ R triple (CD64, CD32, CD16) deficient mice (Figure 8).

\section{Discussion}

SLE is immunologically characterized by the production of a wide variety of autoantibodies and the formation and deposition of immune complexes. Renal involvement in this multiorgan disease is a major cause of morbidity and mortality $(8,9)$. One parameter strongly linked to renal involvement is the presence of anti-C1q autoantibodies (10). In the present study we demonstrate that anti-C1q antibodies are pathogenic to the kidney in conditions of glomerular C1q-containing immune complexes. These data provide essential evidence on how anti-C1q autoantibodies participate in the sequence of events leading to renal inflammation.

Previously, 2 studies have reported the deposition of anti-C1q antibodies in the kidney $(25,26)$ following the administration of high concentrations of human $\mathrm{C} 1 \mathrm{q}$ and anti-human $\mathrm{C} 1 \mathrm{q}$ antibodies in mice. Since the heterologous nature of such reagents may have been responsible for either the deposition or the lack of overt renal disease, we have generated mouse anti-mouse C1q autoantibodies by immunizing $\mathrm{C}_{1} \mathrm{q}^{-/-}$mice with purified mouse $\mathrm{C} 1 \mathrm{q}$. Since $\mathrm{C}_{1 \mathrm{q}} \mathrm{q}^{--}$mice are reported to be autoimmune-prone if on a mixed genetic background (27), we used non-autoimmuneprone $\mathrm{C} 1 \mathrm{q}^{-/-}$mice on a full $\mathrm{C} 57 \mathrm{BL} / 6$ background (28) to avoid the generation of polyreactive autoantibodies. We determined anti-C1q reactivity using an anti-C1q ELISA as described previously (21), under $0.5 \mathrm{M} \mathrm{NaCl}$ buffer conditions to exclude Fc tail interactions with C1q (29). Since IgG2b antibodies can interact with $\mathrm{C} 1 \mathrm{q}$ via their $\mathrm{Fc}$ tails, we used, in all our in vivo experiments, an isotype-matched IgG2b control $\mathrm{mAb}$ that has a similar capacity to interact with C1q via its Fc tail.

Characterization of the mouse anti-mouse $\mathrm{C} 1 \mathrm{q}$ mAb revealed reactivity with different epitopes on mouse $\mathrm{C} 1 \mathrm{q}$ in ELISA. The mAb's JL-1 and JL-2 displayed reactivity toward C1q in splenic sections of WT but not of $\mathrm{C}_{1} \mathrm{q}^{-/-}$mice, confirming their specificity. Since mAb JL-1 also recognized human C1q, we had the unique opportunity to test whether it would be reactive with either the C1q heads or the CLR, since these are only available for human $\mathrm{C} 1 \mathrm{q}$. We found our $\mathrm{mAb}$ to be reactive with the CLR only, which is in fact the same region with which the autoantibodies in mice (ref. 19 and current article) and humans $(21,30)$ are reactive. The 

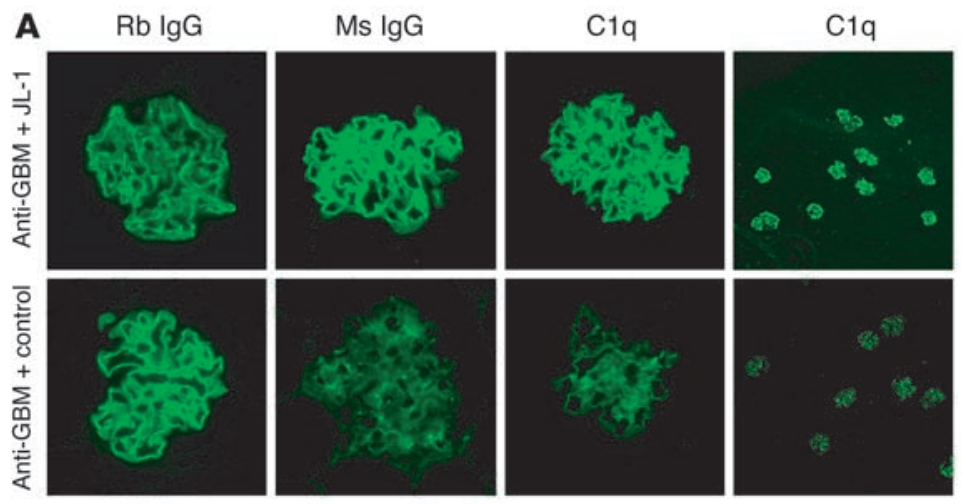

B

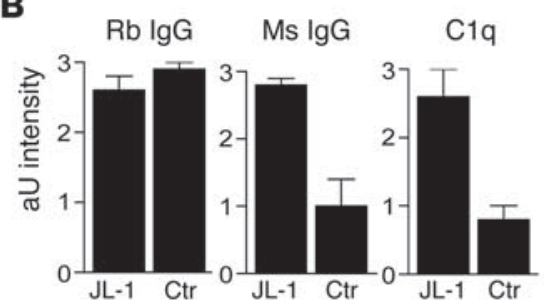

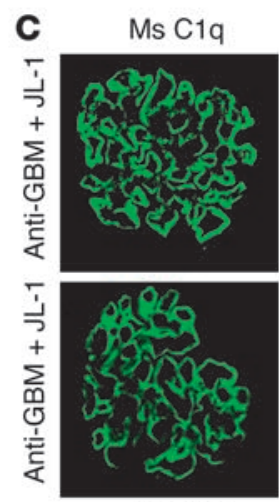

$\mathrm{Rb} \lg \mathrm{G}$

D

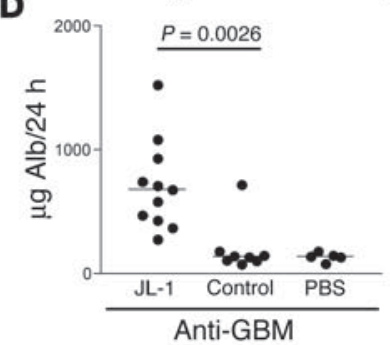

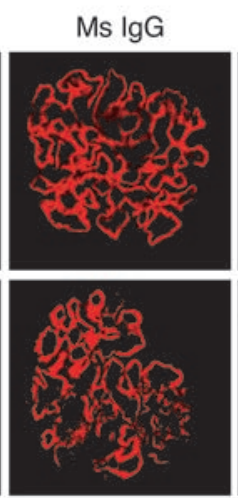

Ms lgG

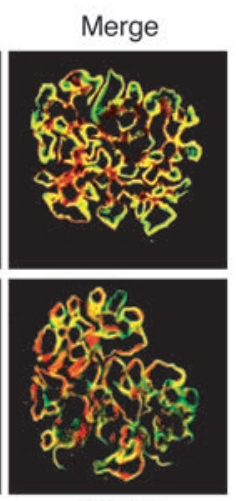

Merge

Figure 4

Effects of administration of anti-C1q mAb to mice pretreated with C1q-fixing anti-GBM antibodies. (A) Immunofluorescence of renal sections obtained from mice pretreated with rabbit $(\mathrm{Rb})$ anti-GBM antibodies combined with either mAb JL-1 or IgG2b control mAb stained for the presence of mouse (Ms) IgG, mouse C1q, or rabbit IgG. Images show linear, GBM-like deposition of anti-GBM antibodies, linear fixation of C1q and anti-C1q in the $\mathrm{JL}-1$-coinjected mice, and only mild mesangial positivity for $\mathrm{C} 1 \mathrm{q}$ and anti-C1q in control-coinjected mice. Original magnification, $\times 400$. Right panels: Low-power magnifications of renal sections of mice injected with anti-GBM in combination with either $\mathrm{JL}-1$ or control and stained for C1q. Original magnification, $\times 100$. (B) Quantification of immunofluorescence analysis of the glomerular deposition of rabbit IgG, mouse IgG, and C1q. Ctr, control. (C) Confocal analysis of kidney sections of mice injected with rabbit anti-GBM and JL-1. Representative pictures are shown for the colocalization (yellow) of mouse C1q (green) and mouse IgG (red) and the colocalization (yellow) of rabbit lgG (green) and mouse IgG (red). They indicate that rabbit IgG, mouse C1q, and mouse IgG do colocalize in these mice, in a linear, GBM-like pattern. (D) Albuminuria of mice injected with anti-GBM antibodies followed by JL-1, control mAb, or PBS.

CLR of C1q is most likely exposed and accessible after binding of C1q to a ligand, whereas the heads are occupied. Based on these observations, we have chosen $\mathrm{mAb} \mathrm{JL}-1$ as the most appropriate $\mathrm{mAb}$ for in vivo testing.

Administration of anti-C1q mAb JL-1 to naive mice resulted in glomerular deposition of both $\mathrm{C} 1 \mathrm{q}$ and anti-C1q autoantibodies, but without overt signs of renal damage. Previously we reported similar findings using a rabbit anti-mouse $\mathrm{C} 1 \mathrm{q}$ polyclonal antibody (31). These results are consistent with the observation that anti-C1q autoantibodies can be found, unrelated to renal problems, in serum of HUVS patients and healthy individuals. Since no renal biopsies are performed without indications of renal problems, to our knowledge there are no data available on glomerular deposition of C1q and IgG in either HUVS or healthy individuals positive for anti-C1q autoantibody.

Injection of JL-1 in mice that had glomerular C1q-containing immune complexes resulted in enhanced renal damage. Several reports describe that the vast majority of SLE patients have glomerular deposits of both IgG and C1q even in the absence of clinically overt renal disease (32-34). This glomerular C1q could potentially serve as a target for anti-C1q autoantibody. Thus, the occurrence of anti-C1q autoantibodies may be highly relevant to the development of nephritis. Although most SLE patients have glomerular immune complexes containing $\mathrm{C} 1 \mathrm{q}$, only those positive for anti-C1q autoantibodies suffer overt renal disease. Con- versely, patients who do not have anti-C1q autoantibodies do not develop nephritis (17). We provide causal evidence to suggest that anti-C1q autoantibodies are essential but not sufficient for the development of full-blown renal inflammation (18).

Although anti-C1q autoantibodies are an important determinant for $\mathrm{LN}$, the degree of disease also seems to correlate with the amount of $\mathrm{C} 1 \mathrm{q}$ present in the glomerulus. For instance, in glomeruli of Rag2 $/ /$ mice, in the absence of glomerular C1q, no deposition takes place and no renal damage occurs. In naive WT mice, trace amounts of $\mathrm{C} 1 \mathrm{q}$ are present in glomeruli, which facilitates the glomerular deposition of anti-C1q autoantibodies; however, this is not sufficient for overt renal damage. Only when there is a relatively high concentration of $\mathrm{C} 1 \mathrm{q}$ in the glomerulus, as is the case for glomerular C1q-containing immune complexes, will anti-C1q autoantibodies not only deposit but also induce overt renal disease.

We verified that the enhanced renal damage observed was the effect of anti-C1q reactivity by testing the combination of the C1qfixing anti-GBM preparation and $\mathrm{JL}-1$ in $\mathrm{C}_{1 \mathrm{q}} \mathrm{q}^{-/}$mice. No enhancement of disease was observed in $\mathrm{C}_{1} \mathrm{q}^{-/-}$mice, which indicates that it was indeed the interaction between anti-C1q autoantibodies and C1q, and not cross-reactivity of mAb JL-1 with rabbit IgG or contaminating factors like endotoxin, that enhanced renal disease in this model (35).

The enhanced renal damage as observed with the combination of anti-GBM antibodies and anti-C1q mAb JL-1 can be explained 
A

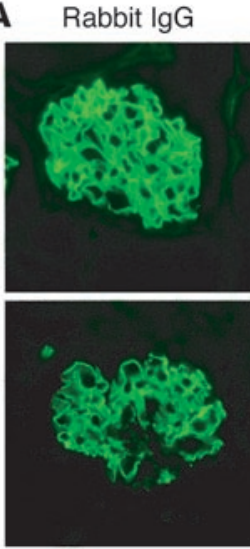

Mouse C1q WT
Rabbit IgG
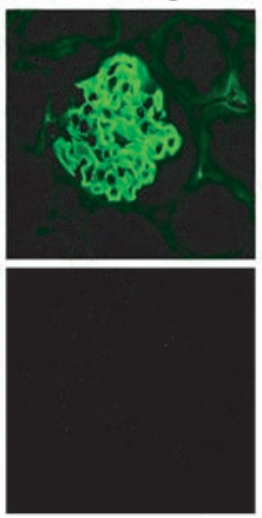

Mouse $\mathrm{C} 1 \mathrm{q}$ $\mathrm{C} 1 \mathrm{q}^{-1-}$
C1q-fixing anti-GBM

B

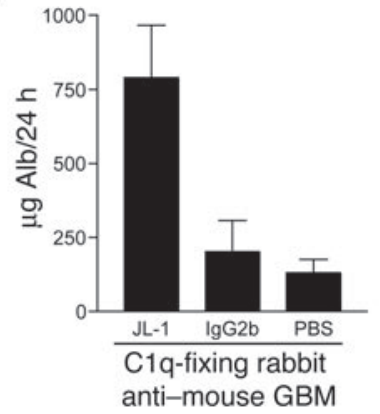

Sheep $\lg G$

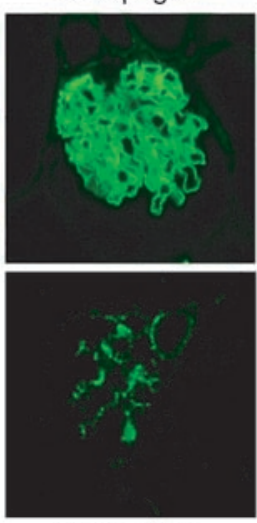

Mouse C1q WT

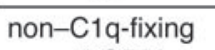

anti-GBM

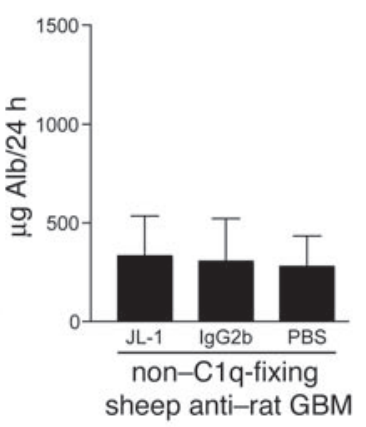

by a "2-hit" model. In this model, binding of anti-GBM antibodies to the GBM and the separate deposition of $\mathrm{C} 1 \mathrm{q}$ and anti-C1q autoantibodies may trigger pathological effects. In an alternative synergistic model, events such as binding of anti-GBM to the GBM, fixation of $\mathrm{C} 1 \mathrm{q}$ by the Fc parts of the anti-GBM, and deposition of anti-C1q autoantibodies on to this immune complex $\mathrm{C} 1 \mathrm{q}$ could converge. We tested the 2 possible mechanisms by using a $\mathrm{C} 1 \mathrm{q}$-fixing and a non-C1q-fixing antiGBM preparation. In the $\mathrm{C} 1 \mathrm{q}$-fixing model, the enhancing effect of JL-1 was observed only in WT, not in $\mathrm{C} 1 \mathrm{q}^{-/-}$mice. It was also absent in the model using a non-C1q-fixing anti-

\section{Figure 6}

Histological changes induced by $\mathrm{JL}-1$ at both the light microscopic and the electron microscopic levels. (A) Histological analysis of Silver-stained renal sections of mice injected with rabbit anti-mouse GBM and coinjected with either mAb JL-1 or IgG2b control mAb, obtained at 24 hours after injection. For JL-1-coinjected mice, images show pronounced inflammatory cell influx, focal capillary tuft occlusion by microthrombi, necrotizing lesions, nuclear debris, and wireloop-like lesions. Control-coinjected mice only display marginal inflammatory cell influx. Original magnification, $\times 400$. (B) Quantification of histological changes using the activity index as described in Methods. (C) Electron microscopic analysis of glomerular lesions of mice injected with rabbit anti-mouse GBM and coinjected with either anti-C1q mAb JL-1 or control mAb IgG2b. At higher magnification, we observed several wireloop-like lesions in the $\mathrm{JL}-1$-coinjected mice, whereas the IgG2b-coinjected mice did not display any abnormalities. Original magnifications, $\times 2,000$ (left) and $\times 4,000$ (right).

\section{Figure 5}

The disease-enhancing effect of $\mathrm{JL}-1$ is dependent on glomerular C1q. (A) Immunofluorescence analysis of anti-GBM antibody deposition and C1q deposition for the C1q-fixing anti-GBM preparation in WT and $\mathrm{C} 1 \mathrm{q}^{-/-}$mice and the non-C1q-fixing anti-GBM preparation in WT mice. The images show the linear IgG fixation for both anti-GBM preparations, but only linear fixation of C1q for the rabbit anti-GBM preparation. Only some mild mesangial C1q positivity can be observed in the mice given sheep anti-GBM. Original magnification, $\times 400$. (B) Groups of WT mice were injected with either the C1q-fixing or the non-C1qfixing anti-GBM preparation and coinjected with $\mathrm{JL}-1$, control, or PBS, and albuminuria was determined.

GBM preparation. This indicates that, in our model, anti-C1q autoantibodies, in the short term, enhances renal disease only in the context of renal C1q-containing immune complexes and, therefore, has a "synergistic" effect.

The damage induced by anti-C1q autoantibodies, in combination with anti-GBM antibodies, involves increased numbers of glomerular granulocytes, capillary tuft occlusion, microthrombi, and wireloop-like lesions. LN is categorized in several WHO classifications, depending on histological abnormalities (8). Many histological criteria of LN are present in the lesions induced by our anti-C1q $\mathrm{mAb}$, such as IgG and $\mathrm{C} 1 \mathrm{q}$ deposition, formation of subendothelial immune deposits, influx of leukocytes, and glomerular tuft occlusion. The fact that our experiments lasted only 24 hours may explain the lack of proliferative lesions or crescent formation.

The mechanism by which these anti-C1q autoantibodies enhance immune complex renal disease involves both complement activation and $\mathrm{Fc}$ receptors. Several reports have described the anti-GBM model as complement-independent (35-37), although others did report an effect of complement $(24,38,39)$. Most likely, the dose of antibody given will determine the dependence on complement. Low concentrations, as used in the present study, are still dependent on complement, whereas high doses of antibody damage the kidney in a complement-independent way (38). In contrast, both concentrations of antibody work Fc receptor-dependently $(37,40)$. We have shown our
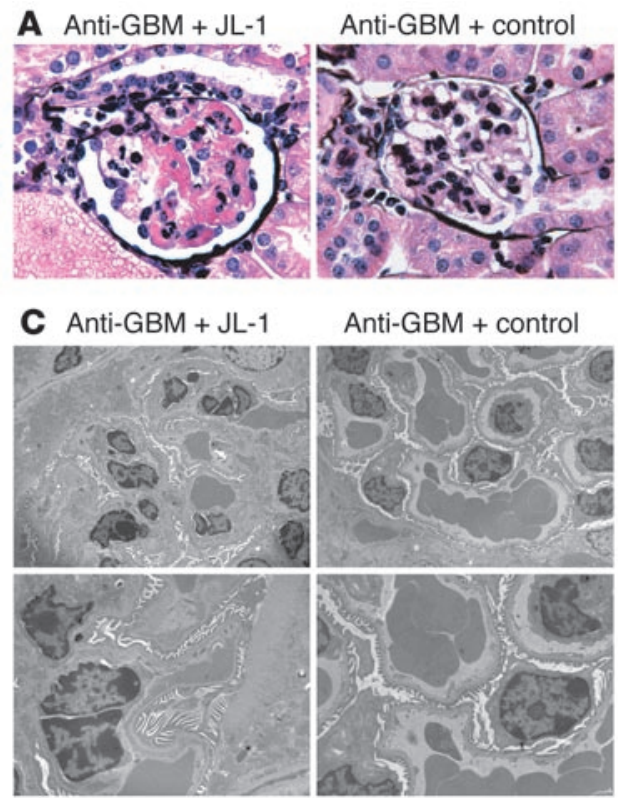

Anti-GBM + control
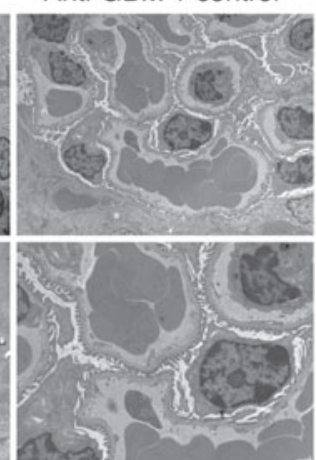

B Anti-GBM + mAb

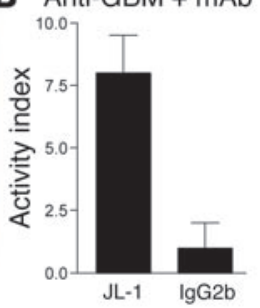


A

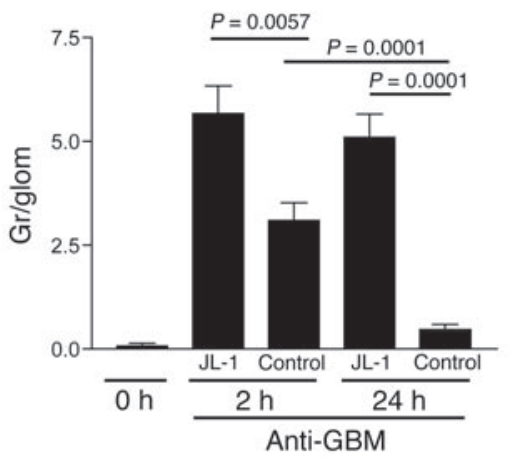

B $\quad$ Anti-GBM $+\mathrm{JL}-1$
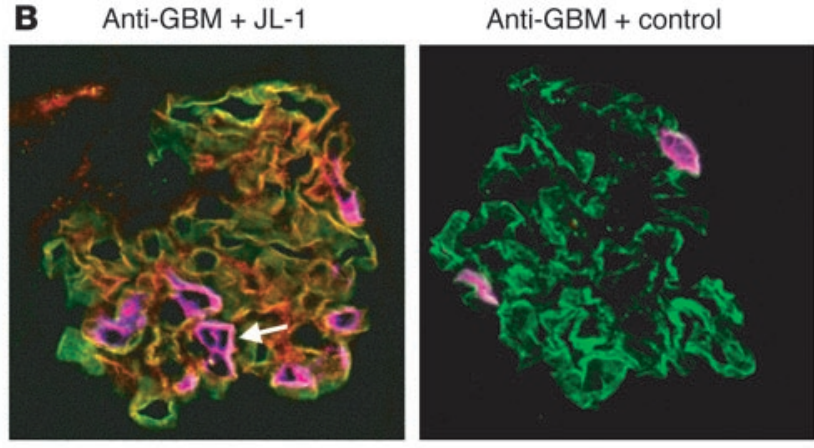

model to be indeed dependent on the $\mathrm{C} 1 \mathrm{q}$, the antigen for anti-C1q autoantibodies, by using $\mathrm{C}^{-} \mathrm{q}^{-/}$mice. Using $\mathrm{C}^{-/-}$mice, we also found that complement activation was essential. Our experiments using $\mathrm{C} 4$ I- mice demonstrate that our model was dependent on $\mathrm{C} 4$ activation, suggesting involvement of either the classical or the lectin pathway of complement activation. Complement activation itself may damage the kidney or it may attract and activate leukocytes, which, in turn, may cause damage via Fcy receptor-dependent mechanisms. Therefore, we have analyzed our model in $\mathrm{Fc} \gamma$ receptor-deficient mice and observed normal deposition of $\mathrm{C} 1 \mathrm{q}$ and anti-C1q but no enhanced albuminuria, which indicates that $\mathrm{Fc} \gamma$ receptor triggering is also important in this model. Based on our data and the literature, we postulate that the sequence of events leading to severe immune complex renal disease is deposition of immune complexes on the GBM (Figure 9A), fixation of C1q from the circulation (Figure 9B), binding of antiC1q autoantibodies (Figure 9C), and massive complement activation and attraction of inflammatory cells (Figure 9D). In conclusion, anti$\mathrm{C} 1 \mathrm{q}$ antibodies induce glomerular deposition of $\mathrm{C} 1 \mathrm{q}$ and anti-C1q in naive mice but do not cause overt renal disease. However, anti-C1q autoantibodies strongly enhance renal disease when C1q-containing immune complexes are present in the glomerulus, which may explain the relationship between these antibodies and nephritis in SLE patients. These data provide essential insight into the mechanisms involved in immune complex-mediated renal inflammation.

\section{Methods}

\section{Animals}

Male C57BL/6 mice (Harlan), C1q-/- C57BL/6 mice (27), C3-/- C57BL/6 mice (41), C4 /- C57BL/6 mice (41), Fc $\gamma \mathrm{R}$ triple -/- (CD64, CD32, CD16) mice (42), and Rag2 $2^{-/}$C57BL/ 6 mice (43) (Taconic) were maintained at our facility. Mice were 8-12 weeks of age and had free access to water and standard chow. Animal care and experimental procedures were performed in accordance with the NIH guidelines for the care and use of laboratory animals.

\section{Figure 7}

Quantification of glomerular granulocyte influx. (A) Mice were injected with anti-GBM antibodies in combination with either $\mathrm{JL}-1$ or control mAb. Granulocytes per glomerular cross section were scored either at 2 hours or at 24 hours after injection. (B) Confocal analysis of sections stained for mouse C1q (green), mouse IgG (red), and mouse granulocytes (purple). The pictures are merged and show, in yellow, colocalization of green and red, and, in white, colocalization of green and purple. The anti-GBM antibodies induced linear fixation of $\mathrm{C} 1 \mathrm{q}$ in both groups, but only in the JL-1-coinjected mice is there colocalization between $\mathrm{C} 1 \mathrm{q}$ and $\mathrm{IgG}$ and a pronounced influx of granulocytes. Original magnification, $\times 400$. The white arrow indicates the white colocalization between $\mathrm{C} 1 \mathrm{q}$ and granulocytes.

\section{Purification and detection of mouse $\mathrm{C} 1 \mathrm{q}$}

Mouse C1q was purified as described previously (31). Briefly, mouse serum (Harlan) was adjusted to $10 \mathrm{mM}$ EDTA and applied to a rabbit IgG Sepharose column. After extensive washing with PBS containing 10 mM EDTA, bound $\mathrm{C} 1 \mathrm{q}$ was eluted using $1 \mathrm{M} \mathrm{NaCl}$ containing $10 \mathrm{mM}$ EDTA. The C1qenriched fractions were identified by ELISA, pooled and dialyzed against PBS, concentrated to $0.5 \mathrm{mg} / \mathrm{ml}$, and stored in aliquots at $-80^{\circ} \mathrm{C}$. Levels of mouse $\mathrm{C} 1 \mathrm{q}$ were detected by sandwich ELISA as described previously (31).

\section{Generation of mouse anti-mouse $\mathrm{C} 1 \mathrm{q} \mathrm{mAb}$}

Anti-C1q mAb's were generated by immunization of $\mathrm{C} 1 \mathrm{q}^{-/-} \mathrm{C} 57 \mathrm{BL} / 6$ mice with purified mouse C1q. Mice were injected subcutaneously with $20 \mu \mathrm{g}$ $\mathrm{C} 1 \mathrm{q}$ in $50 \mu \mathrm{l} \mathrm{CFA}$ (Difco), followed by 3 boosts with $20 \mu \mathrm{g}$ mouse C1q in 50 $\mu \mathrm{l}$ incomplete Freund's adjuvant (Difco) at 2-week intervals. Splenocytes of immunized animals were fused with SP2.0 cells using standard procedures. Cells were grown in IMDM (BioWhittaker Europe) supplemented with $2 \%$ PenStrep (Invitrogen Corp.), $0.5 \mathrm{ng} / \mathrm{ml}$ human IL-6 (PreproTech Inc.), 0.05 $\mathrm{mM} \beta$-mercaptoethanol, and $10 \%$ heat-inactivated FCS (Invitrogen Corp.). Clones were screened for anti-C1q reactivity using an anti-C1q detection ELISA as previously described (21). Briefly, ELISA plates were coated with C1q-binding peptide $2 \mathrm{~J}$ (44) at $12.5 \mu \mathrm{M}$ in coating buffer for 2 hours at $37^{\circ} \mathrm{C}$. Plates were washed and incubated with Rag $2^{-/-}$, Ig-deficient serum as a source of $\mathrm{C} 1 \mathrm{q}$ at 1:20 in PBS containing $0.05 \%$ Tween 20 and $1 \%$ BSA (PBS-T-BSA) for 1 hour at $37^{\circ} \mathrm{C}$. Serial dilutions of samples were incubated in PBS-T-BSA containing $0.5 \mathrm{M} \mathrm{NaCl}$ for 1 hour at $37^{\circ} \mathrm{C}$. Bound mouse IgG was detected using goat anti-mouse IgG conjugated to HRP (DAKO $\mathrm{A} / \mathrm{S}$ ). Data are expressed as OD at $415 \mathrm{~nm}$. Isotypes were determined using an Isotype kit (BD Biosciences - Pharmingen).

Positive clones were subjected to 2 rounds of limiting-dilution selection. Large quantities of $\mathrm{mAb}$ were generated using in vitro culture. Antibody

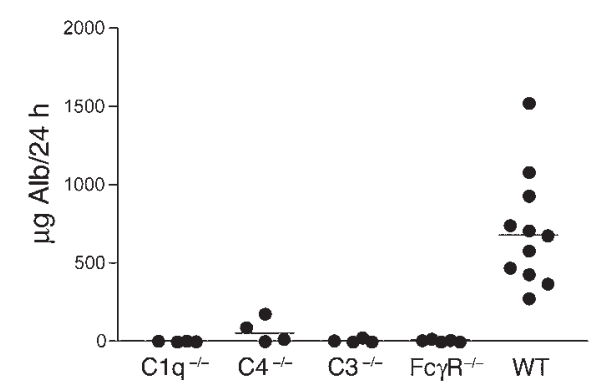

Figure 8

Anti-GBM and JL-1 in various genetically deficient mice. Rabbit antimouse GBM in combination with JL-1 was administered to either WT

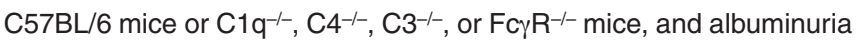
was assessed. 


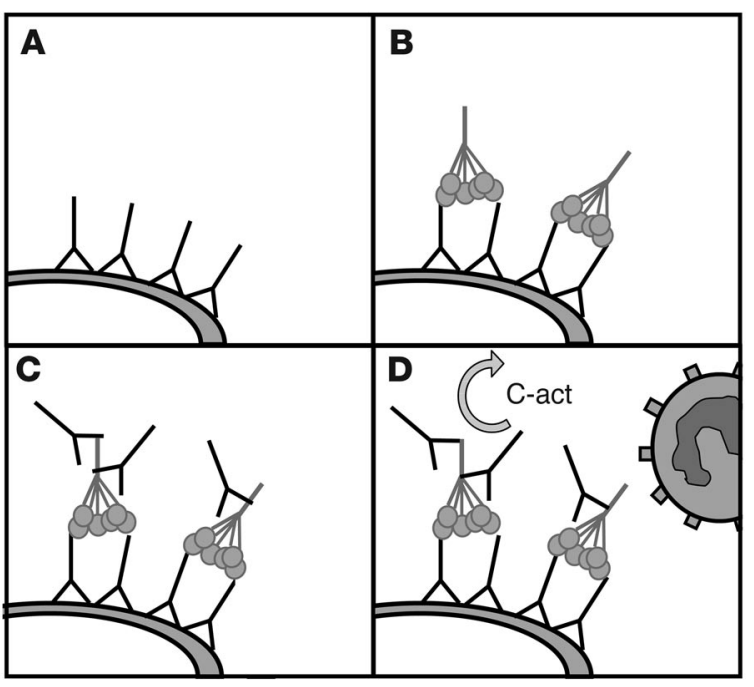

Figure 9

Schematic representation of the pathogenic role of anti-C1q antibodies in immune complex-mediated renal disease. (A) Deposition of immune complexes on the GBM. (B) Fixation of $\mathrm{C} 1 \mathrm{q}$ from the circulation by the immune complexes. (C) Binding of anti-C1q autoantibodies to C1q present on the immune complexes. (D) Activation of complement (C-Act) and attraction of inflammatory cells.

purification was performed using Protein A-Sepharose HT columns (Pharmacia Corp.) for IgG2a and IgG2b antibodies and by precipitation and gel filtration for IgM antibody. Purity of the mAb preparations was verified by SDS-PAGE and found to be consistently more than $90 \%$. As a control we used IgG2b mAb anti-TNP (kindly provided by L. Aarden, Sanquin Research, Amsterdam, The Netherlands). Three stable clones of mouse anti-mouse C1q were obtained, designated JL-1, JL-2, and JL-3.

\section{Characterization of anti-C1q mAb's}

Epitope competition. Fixed amounts of DIG-conjugated anti-C1q $\mathrm{mAb}$ or control mAb IgG2b were coincubated with an excess of nonconjugated anti-C1q mAb or IgG2b in the anti-C1q detection ELISA. Binding of DIG-conjugated $\mathrm{mAb}$ was detected by anti-DIG HRP (Boehringer Mannheim). Data are expressed as percent inhibition compared with noninhibited $\mathrm{mAb}$ binding.

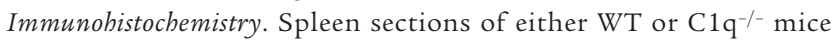
were stained with DIG-conjugated anti-C1q $\mathrm{mAb}$ and DIG-conjugated control antibodies at $5 \mu \mathrm{g} / \mathrm{ml}$ in PBS containing 1\% BSA for 1 hour at room temperature followed by FITC-conjugated anti-DIG (Boehringer Mannheim) at $5 \mu \mathrm{g} / \mathrm{ml}$.

\section{Anti-globular head or-collagen-like tail reactivity of $m A b$ 's}

Recombinant forms of the globular regions of human C1q A, B, and C chains (globular head A [ghA], ghB, and ghC, respectively) were generated as described recently (45). Human CLRs were generated from purified human C1q as described previously $(46,47)$. The recombinant globular regions, CLRs, or human C1q were coated in ELISA, and anti-C1q mAb and control $\mathrm{mAb}$ were incubated at $2.5 \mu \mathrm{g} / \mathrm{ml}$ in PBS-T-BSA and analyzed for binding. Maltose-binding protein (MBP) was used as a negative control protein, since ghA, ghB, and ghC were expressed in bacteria as fusions to Escherichia coli MBP. Anti-CLR reactivity was also analyzed in serum from an autoimmune MRL-lpr mouse of 5 months of age and an age-matched nonautoimmune BALB/c mouse, by coating of CLR and incubation of serially diluted serum.

\section{Generation of anti-GBM antibodies}

A C1q-fixing anti-GBM polyclonal antibody was generated by immunization of male New Zealand white rabbits (Harlan) with purified mouse GBM as described previously (48). Subcutaneous injection of $50 \mu \mathrm{l} \mathrm{GBM}$ mixed with $100 \mu \mathrm{l}$ CFA (Difco) was followed by 3 boosts with $50 \mu$ mouse GBM in $100 \mu \mathrm{l}$ incomplete Freund's adjuvant (Difco) at 2-week intervals. Rabbit immune serum was heat-inactivated at $56^{\circ} \mathrm{C}$ for 30 minutes and centrifuged for 20 minutes at 2,000 g. $\gamma$-Globulin precipitation was performed using $\left(\mathrm{NH}_{4}\right)_{2} \mathrm{SO}_{4}$ at $40 \% \mathrm{wt} / \mathrm{vol}$ saturation, and the precipitate was further purified by anion exchange chromatography using DEAE-Sephacel (Pharmacia Corp.). Rabbit IgG-containing fractions were pooled, concentrated to $20 \mathrm{mg} / \mathrm{ml}$, dialyzed against $0.15 \mathrm{M} \mathrm{NaCl}$, and stored in aliquots at $-20^{\circ} \mathrm{C}$.

Alternatively, we have used the $\gamma-1$ fraction of a sheep anti-rat GBM polyclonal antiserum that cross-reacts with mouse $\operatorname{GBM}(49,50)$. Although this fraction is known to activate mouse complement (51), we previously observed that this preparation does not fix $\mathrm{C} 1 \mathrm{q}$ in vivo.

\section{Experimental procedure}

Groups of 2 C57BL/ 6 mice were injected intraperitoneally with $1 \mathrm{mg}$ of purified anti-C1q $\mathrm{mAb}$ or isotype control in $1 \mathrm{ml}$ of sterile PBS. Blood was collected by tail cut at $0,2,6,12$, and 24 hours after injection. Serum was prepared and stored at $-80^{\circ} \mathrm{C}$. Groups of $5 \mathrm{C} 57 \mathrm{BL} / 6$ mice were injected with $1 \mathrm{mg}$ of purified anti-C1q $\mathrm{mAb}$ intraperitoneally in $1 \mathrm{ml}$ of sterile PBS. Overnight urine was collected by placement of the mice in metabolic cages. Mice were anesthetized with urethane (Sigma-Aldrich) and sacrificed by heart puncture. To exclude cross-reactivity, an additional group of $3 \mathrm{C} 1 \mathrm{q}^{-/-}$mice was injected with $1 \mathrm{mg}$ of mAb JL-1.

Three naive Rag2 ${ }^{-/-}$mice were injected with JL-1. Six Rag2 $2^{-/-}$mice were reconstituted for mouse $\operatorname{IgG}$ by means of mouse $\operatorname{IgG}$ injection as described previously (22). One group of reconstituted mice $(n=3)$ was injected with PBS and the other group $(n=3)$ with JL-1. Both groups were analyzed for the renal deposition of mouse IgG and mouse C1q by immunofluorescence.

Groups of at least 5 mice were injected intravenously with a subnephritogenic dose of either $2 \mathrm{mg}$ rabbit anti-mouse GBM or $0.5 \mathrm{mg}$ sheep anti-rat GBM polyclonal antibodies in a total volume of $200 \mu \mathrm{l}$ sterile PBS via the tail vein, and then injected intraperitoneally 10 minutes later with $1 \mathrm{mg}$ purified mAb JL- 1 or IgG2b in $1 \mathrm{ml}$ sterile PBS or by $1 \mathrm{ml}$ PBS. Overnight urine was collected by placement of the mice in metabolic cages. Mice were anesthetized with urethane (Sigma-Aldrich) and sacrificed by heart puncture at 24 hours. Similarly, an additional 2 groups of 4 mice were injected with the $\mathrm{C} 1 \mathrm{q}$-fixing rabbit anti-GBM antibody in combination with JL-1, IgG2b control antibody, or PBS only, sacrificed at 2 hours, and analyzed for glomerular granulocyte influx as a measure of glomerular inflammation.

The C1q-fixing anti-GBM preparation was administered in combination with JL-1 to groups of $\mathrm{C}_{1} \mathrm{q}^{-/}, \mathrm{C} 4^{-/-}, \mathrm{C}^{-/-}$, and $\mathrm{Fc} \gamma \mathrm{R}$ triple -/- (CD64, $\mathrm{CD} 32, \mathrm{CD} 16)$ mice ( $n=4$ in each group), and urine was collected and analyzed for albuminuria.

\section{Histological analysis}

Immediately after sacrifice, 1 kidney from each mouse was frozen in precooled 2-methylbutane for immunohistochemistry, and the other was fixed in methyl Carnoy's solution for light microscopy.

For immunofluorescence, cryostat sections of $3 \mu \mathrm{m}$ were fixed using acetone, all antibodies were diluted in PBS containing 1\% BSA, and sections were incubated in a humid incubator for 1 hour at room temperature. Sections were washed 3 times for 5 minutes using PBS. Sections were stained for the presence of mouse IgG, rabbit IgG, and mouse C1q using goat antimouse IgG Oregon Green (Invitrogen Corp.), goat anti-rabbit IgG conjugated to FITC (Nordic Immunological Laboratories), and rabbit anti-mouse 
C1q DIG, followed by sheep anti-DIG conjugated to HRP, where appropriate. Evaluation of the extent and intensity of immunofluorescence was performed by scoring of the intensity of staining for individual glomeruli as 0 (negative), 1 (positive above background), 2 (positive), and 3 (brightly positive) for at least 20 glomeruli per section. Means and SDs for at least 3 mice per group are shown. For double staining, goat anti-mouse IgG Alexa 546 (Invitrogen Corp.) was used in combination with anti-C1q and antirabbit IgG stainings, as described above. For triple staining, the antibodies described above were combined with rat anti-mouse granulocyte $\mathrm{mAb}$ GR-1 (a kind gift of G. Kraal, Vrije Universiteit Medisch Centrum, Amsterdam, The Netherlands), and rat IgG was detected using goat anti-rat IgG Alexa 594 (Invitrogen Corp.). The double- and triple-stained sections were mounted in Mowiol 40-88 (Sigma-Aldrich Chemie) and examined using an LSM 510 confocal microscope (Carl Zeiss AG).

For immunohistochemistry, sections were stained for mouse granulocytes using rat anti-mouse granulocyte $\mathrm{mAb}$ GR-1, and rat IgG was detected using goat anti-rat IgG conjugated to HRP (DAKO), preincubated with $10 \%$ normal mouse serum to absorb anti-mouse IgG cross-reactivity. NovaRED (Vector Laboratories Inc.) was used as a substrate. Granulocyte influx was scored by counting of the number of granulocytes per glomerular cross section. Granulocytes were counted by 2 observers on coded sections.

For light microscopy, the other kidney was fixed and embedded in paraffin, and $3-\mu \mathrm{m}$ sections were stained with H\&E, periodic acid-Schiff, and silver. Evaluation of histopathological changes was performed by a pathologist who was blinded to the code of the sections, using the activity index as described by Austin et al. (23). This index scores several parameters of active renal inflammation, such as glomerular proliferation, leukocyte exudation, karyorrhexis/fibrinoid necrosis, and hyaline deposits.

For electron microscopy, small pieces of cortex were fixed in $1 \%$ paraformaldehyde $1.5 \%$ glutaraldehyde overnight and washed in $0.1 \mathrm{M}$ cacodylate buffer. Pieces of kidney were postfixed in $1 \% \mathrm{OsO}_{4}$, dehydrated, embedded in Epon 812, and cut into ultrathin sections using a Leica UCT ultramicrotome (Leica Microsystems Inc.). On the grids, sections were poststained with uranyl acetate and lead citrate and examined with a JEM1011 electron microscope (JEOL USA Inc.).

\section{Renal damage}

Renal damage was determined by analysis of urinary albumin excretion using an autoanalyzer (Hitachi 911; Roche). Data are expressed as micrograms albumin excreted in urine per 24 hours.

\section{Statistical analysis}

Statistical analysis was performed using GraphPad Prism 3.03 software (GraphPad Software Inc.). Differences between parameters were analyzed using unpaired Student's $t$ tests. The $P$ values were considered statistically significant at $P$ less than 0.05 .

\section{Acknowledgments}

This work was supported by grant 98.1763 from the Dutch Kidney Foundation, NIH grant DK30932 (to D.J. Salant), and a grant from the European Union (QLG1-CT2002-01215). The authors wish to thank Vanessa van Ham, Kyra Gelderman, Roelof Flierman, and Ellen van der Voort for excellent technical support, J.W. Drijfhout for valuable reagents for the present study, and T. Huizinga for his comments on the manuscript (all from Leiden University Medical Center, Leiden, The Netherlands).

Received for publication January 15, 2004, and accepted in revised form June 29, 2004.

Address correspondence to: Mohamed R. Daha, Department of Nephrology, C3, Leiden University Medical Center, Albinusdreef 2, 2333 ZA Leiden, The Netherlands. Phone: 31715263964; Fax: 31715248118; E-mail: m.r.daha@lumc.nl.
1. Lipsky, P.E. 2001. Systemic lupus erythematosus: an autoimmune disease of B cell hyperactivity. Nat. Immunol. 2:764-766.

2. Mok, C.C., and Lau, C.S. 2003. Pathogenesis of systemic lupus erythematosus. J. Clin. Pathol. 56:481-490.

3. Mills, J.A. 1994. Systemic lupus erythematosus. N. Engl. J. Med. 330:1871-1879.

4. Tsao, B.P. 2003. The genetics of human systemic lupus erythematosus. Trends Immunol. 24:595-602.

5. Walport, M.J. 2001. Complement. First of two parts. N. Engl. J. Med. 344:1058-1066.

6. Walport, M.J. 2001. Complement. Second of two parts. N. Engl. J. Med. 344:1140-1144.

7. Trouw, L.A., Roos, A., and Daha, M.R. 2001. Autoantibodies to complement components. Mol. Immunol. 38:199-206.

8. Cameron, J.S. 1999. Lupus nephritis. J. Am. Soc. Nephrol. 10:413-424.

9. Davis, J.C., Tassiulas, I.O., and Boumpas, D.T. 1996. Lupus nephritis. Curr. Opin. Rheumatol. 8:415-423.

10. Seelen, M.A., Trouw, L.A., and Daha, M.R. 2003. Diagnostic and prognostic significance of antiC1q antibodies in systemic lupus erythematosus. Curr. Opin. Nephrol. Hypertens. 12:619-624.

11. Horvath, L., et al. 2001. High levels of antibodies against Clq are associated with disease activity and nephritis but not with other organ manifestations in SLE patients. Clin. Exp. Rheumatol. 19:667-672.

12. Siegert, C., Daha, M., Westedt, M.L., van der Voort, E., and Breedveld, F. 1991. IgG autoantibodies against $\mathrm{C} 1 \mathrm{q}$ are correlated with nephritis, hypocomplementemia, and dsDNA antibodies in systemic lupus erythematosus. J. Rheumatol. 18:230-234.

13. Coremans, I.E., et al. 1995. Changes in antibodies to $\mathrm{C} 1 \mathrm{q}$ predict renal relapses in systemic lupus erythematosus. Am. J. Kidney Dis. 26:595-601.

14. Moroni, G., et al. 2001. Anti-C1q antibodies may help in diagnosing a renal flare in lupus nephritis. Am. J. Kidney Dis. 37:490-498.

15. Mannik, M., and Wener, M.H. 1997. Deposition of antibodies to the collagen-like region of $\mathrm{C} 1 \mathrm{q}$ in renal glomeruli of patients with proliferative lupus glomerulonephritis. Arthritis Rheum. 40:1504-1511.

16. Mannik, M., Merrill, C.E., Stamps, L.D., and Wener, M.H. 2003. Multiple autoantibodies form the glomerular immune deposits in patients with systemic lupus erythematosus. J. Rheumatol. 30:1495-1504

17. Fremeaux-Bacchi, V., Noel, L.H., and Schifferli, J.A. 2002. No lupus nephritis in the absence of antiC1q autoantibodies? Nephrol. Dial. Transplant. 17:2041-2043.

18. Trendelenburg, M., Marfurt, J., Gerber, I., Tyndall, A., and Schifferli, J.A. 1999. Lack of occurrence of severe lupus nephritis among anti-C1q autoantibody-negative patients. Arthritis Rheum. 42:187-188.

19. Hogarth, M.B., et al. 1996. Autoantibodies to the collagenous region of $\mathrm{C} 1 \mathrm{q}$ occur in three strains of lupus-prone mice. Clin. Exp. Immunol. 104:241-246.

20. Trinder, P.K., Maeurer, M.J., Schorlemmer, H.U., and Loos, M. 1995. Autoreactivity to mouse C1q in a murine model of SLE. Rheumatol. Int. 15:117-120.

21. Uwatoko, S., et al. 1987. C1q solid-phase radioimmunoassay: evidence for detection of antibody directed against the collagen-like region of $\mathrm{C} 1 \mathrm{q}$ in sera from patients with systemic lupus erythematosus. Clin. Exp. Immunol. 69:98-106.

22. Trouw, L.A., Duijs, J.M., Van Kooten, C., and Daha, M.R. 2003. Immune deposition of C1q and anti-C1q antibodies in the kidney is dependent on the presence of glomerular IgG. Mol. Immunol. 40:595-602.

23. Austin, H.A., III, Muenz, L.R., Joyce, K.M., Antonovych, T.T., and Balow, J.E. 1984. Diffuse proliferative lupus nephritis: identification of specific pathologic features affecting renal outcome. Kidney Int. 25:689-695.

24. Hebert, M.J., et al. 1998. Acute nephrotoxic serum nephritis in complement knockout mice: relative roles of the classical and alternate pathways in neutrophil recruitment and proteinuria. Nephrol. Dial. Transplant. 13:2799-2803.

25. Coremans, I.E., et al. 1995. Stabilization of glomerular deposits of $\mathrm{C} 1 \mathrm{q}$ by antibodies against C1q in mice. J. Clin. Lab. Immunol. 44:47-61.

26. Uwatoko, S., Gauthier, V.J., and Mannik, M. 1991. Autoantibodies to the collagen-like region of C1Q deposit in glomeruli via C1Q in immune deposits. Clin. Immunol. Immunopathol. 61:268-273.

27. Botto, M., et al. 1998. Homozygous C1q deficiency causes glomerulonephritis associated with multiple apoptotic bodies. Nat. Genet. 19:56-59.

28. Mitchell, D.A., et al. 2002. C1q deficiency and autoimmunity: the effects of genetic background on disease expression. J. Immunol. 168:2538-2543.

29. Kohro-Kawata, J., Wener, M.H., and Mannik, M. 2002. The effect of high salt concentration on detection of serum immune complexes and autoantibodies to $\mathrm{C} 1 \mathrm{q}$ in patients with systemic lupus erythematosus. J. Rheumatol. 29:84-89.

30. Wener, M.H., Uwatoko, S., and Mannik, M. 1989. Antibodies to the collagen-like region of $\mathrm{C} 1 \mathrm{q}$ in sera of patients with autoimmune rheumatic diseases. Arthritis Rheum. 32:544-551.

31. Trouw, L.A., et al. 2003. Glomerular deposition 
of $\mathrm{C} 1 \mathrm{q}$ and anti-C1q antibodies in mice following injection of antimouse C1q antibodies. Clin. Exp. Immunol. 132:32-39.

32. Berden, J.H. 1997. Lupus nephritis. Kidney Int 52:538-558.

33. Eiser, A.R., Katz, S.M., and Swartz, C. 1979. Clinically occult diffuse proliferative lupus nephritis. An age-related phenomenon. Arch. Intern. Med. 139:1022-1025.

34. Zabaleta-Lanz, M., et al. 2003. Silent nephritis in systemic lupus erythematosus. Lupus. 12:26-30.

35. Robson, M.G., Cook, H.T., Pusey, C.D., Walport, M.J., and Davies, K.A. 2003. Antibody-mediated glomerulonephritis in mice: the role of endotoxin, complement and genetic background. Clin. Exp. Immunol. 133:326-333.

36. Suzuki, Y., et al. 1998. Distinct contribution of Fc receptors and angiotensin II-dependent pathways in anti-GBM glomerulonephritis. Kidney Int. 54:1166-1174.

37. Wakayama, H., et al. 2000. Abolition of antiglomerular basement membrane antibody-mediated glomerulonephritis in FcRgamma-deficient mice. Eur. J. Immunol. 30:1182-1190.

38. Sheerin, N.S., Springall, T., Carroll, M.C., Hartley, B., and Sacks, S.H. 1997. Protection against anti- glomerular basement membrane (GBM)-mediated nephritis in C3- and C4-deficient mice. Clin. Exp. Immunol. 110:403-409.

39. Sheerin, N.S., Springall, T., Abe, K., and Sacks, S.H 2001. Protection and injury: the differing roles of complement in the development of glomerular injury. Eur. J. Immunol. 31:1255-1260.

40. Park, S.Y., et al. 1998. Resistance of Fc receptordeficient mice to fatal glomerulonephritis. J. Clin. Invest. 102:1229-1238.

41. Wessels, M.R., et al. 1995. Studies of group B streptococcal infection in mice deficient in complement component $\mathrm{C} 3$ or $\mathrm{C} 4$ demonstrate an essential role for complement in both innate and acquired immunity. Proc. Natl. Acad. Sci. U. S. A. 92:11490-11494.

42. Ioan-Facsinay, A., et al. 2002. FcgammaRI (CD64) contributes substantially to severity of arthritis, hypersensitivity responses, and protection from bacterial infection. Immunity. 16:391-402.

43. Shinkai, Y., et al. 1992. RAG-2-deficient mice lack mature lymphocytes owing to inability to initiate V(D)J rearrangement. Cell. 68:855-867.

44. Roos, A., et al. 2001. Specific inhibition of the classical complement pathway by C1q-binding peptides. J. Immunol. 167:7052-7059.

45. Kishore, U., et al. 2003. Modular organization of the carboxyl-terminal, globular head region of human $\mathrm{C} 1 \mathrm{q} \mathrm{A}, \mathrm{B}$, and C chains. J. Immunol. 171:812-820.

46. Daha, M.R., Klar, N., Hoekzema, R., and van Es, L.A. 1990. Enhanced Ig production by human peripheral lymphocytes induced by aggregated C1q. J. Immunol. 144:1227-1232.

47. Siegel, R.C., and Schumaker, V.N. 1983. Measurement of the association constants of the complexes formed between intact $\mathrm{C} 1 \mathrm{q}$ or pepsin-treated $\mathrm{C} 1 \mathrm{q}$ stalks and the unactivated or activated $\mathrm{C} 1 \mathrm{r} 2 \mathrm{C} 1 \mathrm{~s} 2$ tetramers. Mol. Immunol. 20:53-66.

48. Baelde, H.J., Bergijk, E.C., and Bruijn, J.A. 1990. Isolation and characterization of mouse glomerular basement membrane. J. Clin. Lab. Immunol. 33:17-20.

49. Lin, F., Emancipator, S.N., Salant, D.J., and Medof, M.E. 2002. Decay-accelerating factor confers protection against complement-mediated podocyte injury in acute nephrotoxic nephritis. Lab. Invest. 82:563-569.

50. Salant, D.J., and Cybulsky, A.V. 1988. Experimental glomerulonephritis. Methods Enzymol. 162:421-461.

51. Quigg, R.J., et al. 1998. Blockade of antibodyinduced glomerulonephritis with Crry-Ig, a soluble murine complement inhibitor. J. Immunol. 160:4553-4560. 